\title{
Recovery of Lattice Defects in Cementite in Cold-Rolled Carbon Steels*
}

\author{
By Akihisa Inoue**, Tsugio Ogura** and Tsuyoshi Masumoto**
}

\begin{abstract}
Transmission electron microscopic observations were made on the recovery process of lattice defects in cementite in high carbon steels annealed after $92 \%$ cold rolling. Thermomagnetic and $\mathrm{X}$-ray analyses were also performed as additional examinations.

No observable change in the defect structure of cementite occurs at temperatures below about $400^{\circ} \mathrm{C}$. Annealing at higher temperatures results in the disappearance of the moiré pattern, a considerable decrease of dislocation density and the formation of well-developed subboundaries. Above about $600^{\circ} \mathrm{C}$, these defects disappear gradually with the progress of spheroidization. These results suggest that the recovery of lattice defects in cementite is caused by polygonization accompanied by climbing or cross slipping of dislocations.
\end{abstract}

(Received March 31, 1977)

\section{Introduction}

The present authors have investigated the deformation and fracture behaviors of cementite in steels by cold rolling ${ }^{(1) \sim(4)}$ and by tension $^{(4) \sim(6)}$, mainly by transmission electron microscopy. It has been shown that a large number of lattice defects such as dislocations and stacking faults are introduced into cementite by deformation. For instance, the dislocation density in cementite increases to the order of $10^{10} / \mathrm{cm}^{2}$ by $92 \%$ cold rolling. This fact suggests that the deformation of cementite occurs in a tolerable degree prior to its fracture. It is therefore very interesting to examine the recovery process of these lattice defects in connection with the spheroidization of cementite. Up to date, the change in the shape of cementite in cold-worked steels by annealing has been observed only by optical and replica electron microscopy, and detailed information has not been obtained on the recovery of cementite. The purpose of the present investigation is to examine by transmission electron microscopy the recovery of lattice defects in cementite in steels annealed after cold rolling.

* This paper was originally published in Japanese in J. Japan Inst. Metals, 40 (1976), 874.

** The Research Institute for Iron, Steel and Other Metals, Tohoku University, Sendai 980, Japan.

\section{Experimental}

Two kinds of plain carbon steels containing $1.23 \% \mathrm{C}$ and $1.25 \% \mathrm{C}$ were used. Their chemical compositions are shown in Table 1 . The steels were prepared from electrolytic iron and white pig iron by induction melting in argon atmosphere. The ingots were hot-rolled and then cold-rolled to produce strips with $2 \mathrm{~mm}$ and $5 \mathrm{~mm}$ in thickness. They were austenitized at $1000^{\circ} \mathrm{C}$ for $30 \mathrm{~min}$ in argon atmosphere, followed by furnace cooling to obtain a large size of lamellar pearlitic cementite. The plates of $5 \mathrm{~mm}$ thick were cold-rolled to $1 \mathrm{~mm}$ and those of $2 \mathrm{~mm}$ thick to $0.16 \mathrm{~mm}$. The respective reductions correspond to $80 \%$ and $92 \%$.

Some of the plates were heated for $5 \mathrm{~h}$ at various temperatures in a temperature range from 200 to $700^{\circ} \mathrm{C}$ and the others for various periods up to $15 \mathrm{~h}$ at $700^{\circ} \mathrm{C}$, followed by water cooling. The annealed plates were thinned to about $50 \mu \mathrm{m}$ by chemical polishing in a solution containing hydrogen peroxide $(100 \mathrm{~m} \ell)$ and hydrofluoric acid $(5 \mathrm{~m} \ell)$, and finally electropolished by a modified Bollmann-method in an electrolyte containing $100 \mathrm{~g}$ of chromic acid and $200 \mathrm{~m} \ell$ of phosphoric acid. An HU-11 type of electron microscope was used at $100 \mathrm{kV}$ with a tilting device of $10^{\circ}$.

Optical microscopic observations, X-ray

Trans. JIM

1977 Vol. 18 
Table 1 Chemical composition of specimens (wt \%).

\begin{tabular}{cccccccccc}
\hline \hline Specimen & $\mathrm{C}$ & $\mathrm{Si}$ & $\mathrm{Mn}$ & $\mathrm{Ni}$ & $\mathrm{Cr}$ & $\mathrm{Al}$ & $\mathrm{P}$ & $\mathrm{S}$ & $\mathrm{Fe}$ \\
\hline No. 1 & 1.23 & 0.018 & 0.002 & 0.004 & 0.001 & - & 0.002 & 0.001 & Bal. \\
No. 2 & 1.25 & 0.024 & $\mathbf{0 . 0 0 1}$ & 0.001 & 0.003 & 0.098 & 0.004 & 0.004 & Bal. \\
\hline \hline
\end{tabular}

diffraction, thermomagnetic analysis and Vickers hardness tests were also made. In $\mathrm{X}$-ray diffraction, $\mathrm{Co}-\mathrm{K} \alpha$ radiation was used. The intensities of diffraction lines from 112, 021,113 and 122 planes of cementite were measured by the point-counting method. In the magnetic analysis a magnetic balance with high sensitivity was used under a magnetic field of $3300 \mathrm{Oe}$. The specimen used was about $1 \mathrm{mg}$ prepared by chemical polishing.

\section{Results and Discussion}

\section{Optical microscopy}

Optical microscopic observations were made to examine a structural change in the $92 \%$ cold-rolled $1.25 \% \mathrm{C}$ steel by annealing for $5 \mathrm{~h}$ at various temperatures. At temperatures below $400^{\circ} \mathrm{C}$ no appreciable change in the morphology of cementite was observed. The coalescence and spheroidization of cementite began above about $400^{\circ} \mathrm{C}$ and became remarkable above $600^{\circ} \mathrm{C}$. Such a spheroidization process is quite similar to those reported in previous papers ${ }^{(7)(8)}$.

\section{Ultimate tensile strength and Vickers hardness}

In Fig. 1, changes in the ultimate tensile strength $\sigma$ and the Vickers hardness $\mathrm{Hv}$ are shown for $1.25 \% \mathrm{C}$ steel cold-rolled to $80 \%$ reduction as a function of the annealing temperature in the case of annealing for $5 \mathrm{~h}$. The annealing at $300^{\circ} \mathrm{C}$ results in an increase in hardness and strength, which decrease sharply in the temperature range from 300 to $500^{\circ} \mathrm{C}$ and gradually above $500^{\circ} \mathrm{C}$. The observed sharp drops are undoubtly due to the recrystallization of ferrite matrix, while the increases in strength and hardness around $300^{\circ} \mathrm{C}$ are caused by a static strain-aging effect in the ferrite matrix ${ }^{(9)(10)}$.

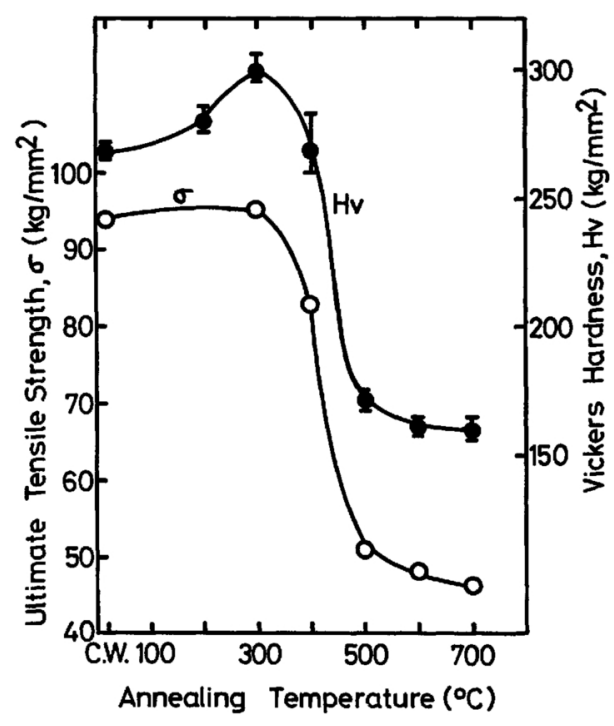

Fig. 1 Changes in ultimate tensile strength $\sigma$ and Vickers hardness $\mathrm{Hv}$ of $1.25 \% \mathrm{C}$ steel by annealing for $5 \mathrm{~h}$ at various temperatures after $80 \%$ cold rolling. C.W.: Cold Working.

\section{Transmission electron microscopy}

The above results show that the recrystallization of ferrite takes place above about $400^{\circ} \mathrm{C}$, and the coalescence and spheroidization of cementite take place above about $600^{\circ} \mathrm{C}$. In this section is described the results of transmission electron microscopic observation of the recovery process of lattice defects in cementite during annealing.

Photograph 1 shows the internal defects in cementite for $1.25 \% \mathrm{C}$ steel cold-rolled to $92 \%$ reduction. A large number of dislocations and diffraction contrasts such as the moiré pattern and strain markings are seen in cementite plates. The corresponding selected area electron diffraction pattern indicates that the cementite lattice is heavily deformed.

Such a defect structure of cementite is not appreciably influenced by annealing below $400^{\circ} \mathrm{C}$. In contrast, the structure of the fer- 

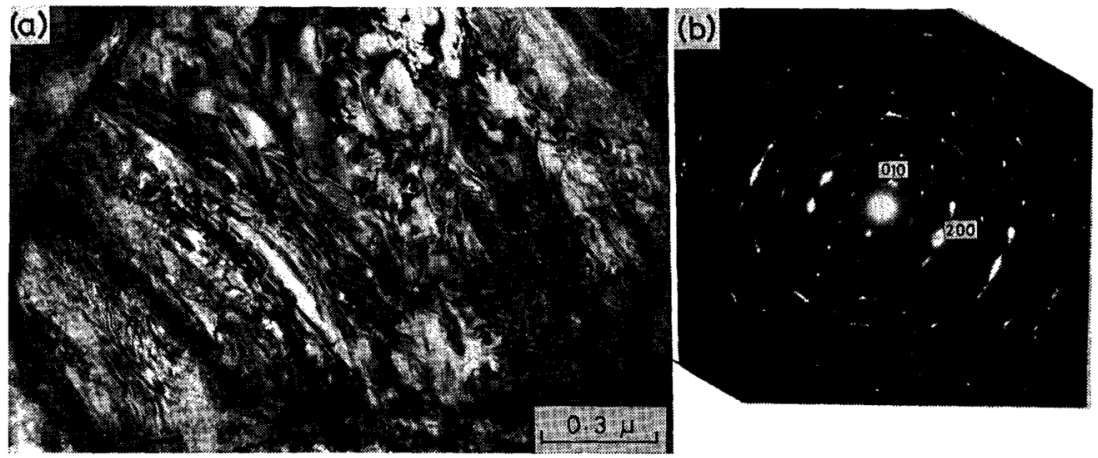

Photo. 1 (a) Transmission electron micrograph showing the internal defects of cementite in $1.25 \% \mathrm{C}$ steel cold-rolled to $92 \%$ reduction after furnace cooling. (b) Selected area electron diffraction pattern.

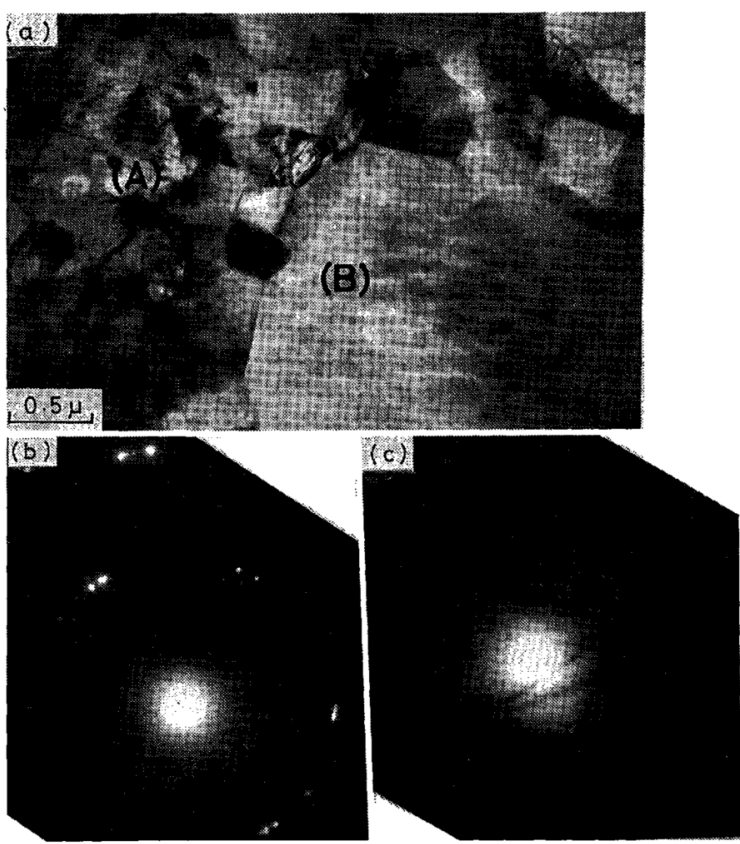

Photo. 2 (a) Transmission electron micrograph showing the recrystallization of ferrite in $1.25 \% \mathrm{C}$ steel annealed for $5 \mathrm{~h}$ at $400^{\circ} \mathrm{C}$ after $92 \%$ cold rolling. (b) and (c). Selected area electron diffraction patterns taken from the regions $A$ and $B$, respectively.

rite matrix changes remarkably by annealing below $400^{\circ} \mathrm{C}$. Well-defined subgrains are observed in the ferrite matrix in $1.25 \% \mathrm{C}$ steel annealed for $5 \mathrm{~h}$ at $300^{\circ} \mathrm{C}$. In the specimen annealed for $5 \mathrm{~h}$ at $400^{\circ} \mathrm{C}$, partially recrystallized grains are observed as shown in Photo. 2(a). These grains seem to have been formed either by the migration of subboundaries ${ }^{(11)(12)}$ or by the coalescence of subgrains ${ }^{(13) \sim(15)}$.

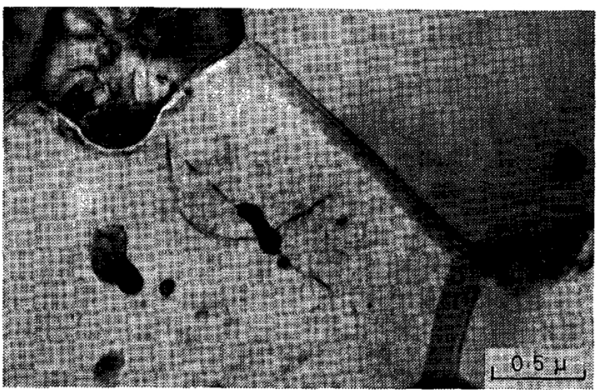

Photo. 3 Transmission electron micrograph showing the coarsening of cementite in $1.25 \% \mathrm{C}$ steel annealed for $5 \mathrm{~h}$ at $500^{\circ} \mathrm{C}$ after $92 \%$ cold rolling.

The diffraction pattern (b) taken from the region A gives splitted diffraction spots, indicating remarkable polygonization of ferrite, whereas the diffraction pattern (c) taken from the region $B$ gives distinct Kikuchi lines $^{(16)}$, suggesting the formation of defectfree ferrite. Thus, the recrystallization of the ferrite matrix can be said to take place inhomogeniously at the initial stage of annealing. This is similar to the case of heavily rolled $\alpha$-iron ${ }^{(17)(18)}$.

Photograph 3 shows a microstructure of $1.25 \% \mathrm{C}$ steel annealed for $5 \mathrm{~h}$ at $500^{\circ} \mathrm{C}$. This photograph indicates that cementite particles smaller than several thousands $\AA$ in diameter might be absorbed into larger cementite particles present on the grain boundaries of ferrite. Such a growth process of cementite is similar to that suggested by Sato et al. ${ }^{(7)}$ In large cementite particles with diameters more than several $\mu \mathrm{m}$, no appreciable change in the defect structure is observed even after 
annealing for $5 \mathrm{~h}$ at $500^{\circ} \mathrm{C}$. This fact suggests that the recovery temperature of cementite is considerably higher than that of ferrite (about $300^{\circ} \mathrm{C}$ ).

Another microstructure after annealing for $5 \mathrm{~h}$ at $500^{\circ} \mathrm{C}$ is shown in Photo. 4. A recovery region and an unrecovery region are coexistent in the same cementite particle as marked by A and $\mathrm{B}$ respectively in photograph (a): in the region $\mathrm{A}$ few dislocations are present, but in the region $\mathrm{B}$ dislocations are still densely populated. The photographs (b) and (c) are diffraction patterns taken from the respective regions $\mathrm{A}$ and $\mathrm{B}$. Both regions have the surfaces nearly perpendicular to the $[001]_{\theta}$ direction and the orientation difference is small. Photograph 5 shows a defect structure of cementite annealed for $5 \mathrm{~h}$ at $600^{\circ} \mathrm{C}$. Dense dislocations and strain markings are no longer observed, but dislocation networks formed by polygonization are observed. Spacings between the dislocations constituting the networks are still very small (about $350 \AA$ ), indicating that the lattice is inclined in a large degree at the
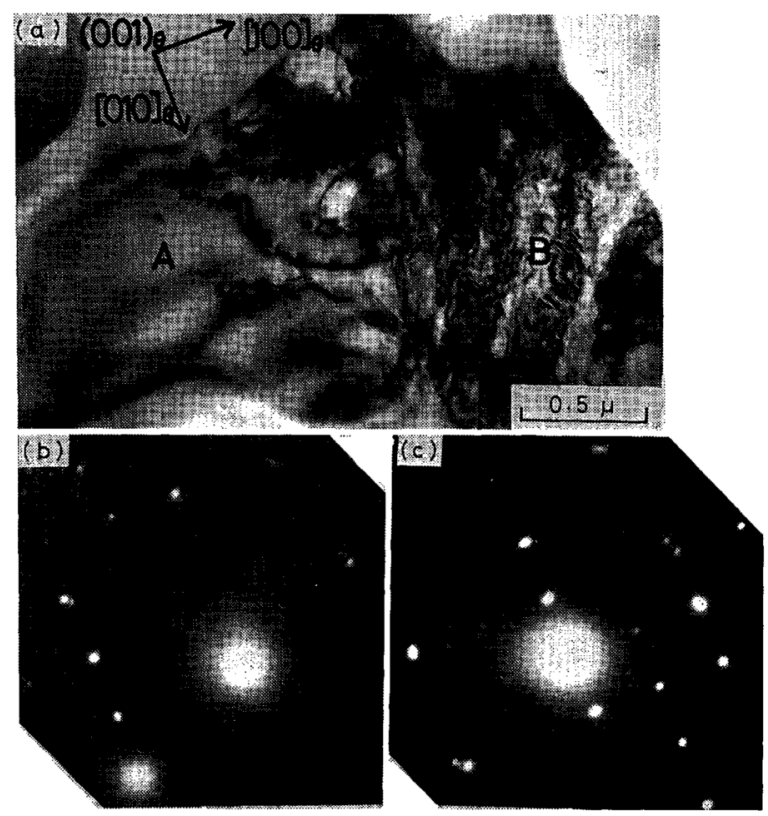

Photo. 4 (a) Transmission electron micrograph showing the recovery of cementite in $1.25 \% \mathrm{C}$ steel annealed for $5 \mathrm{~h}$ at $500^{\circ} \mathrm{C}$ after $92 \%$ cold rolling. (b) and (c). Selected area diffraction patterns taken from the regions $A$ and $B$, respectively.

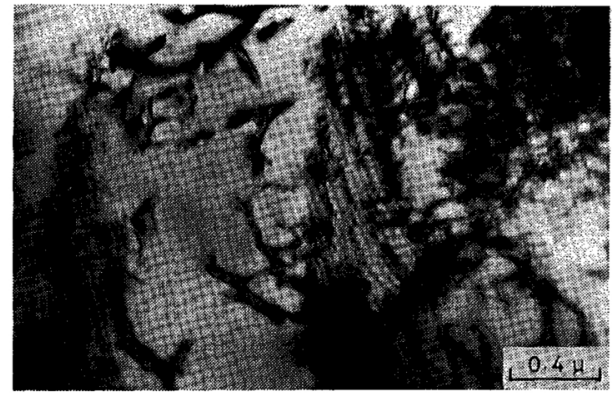

Photo. 5 Transmission electron micrograph showing the formation of subboundaries in cementite in $1.25 \% \mathrm{C}$ steel annealed for $5 \mathrm{~h}$ at $600^{\circ} \mathrm{C}$ after $92 \%$ cold rolling.

subboundary. This spacing increases to several thousand $\AA$ by annealing at $700^{\circ} \mathrm{C}$.

Further detailed observations were made on the defect structure of cementite annealed for various periods up to $15 \mathrm{~h}$ at $700^{\circ} \mathrm{C}$. In the case of annealing for $0.5 \mathrm{~h}$, both the recovery and the unrecovery regions coexist in the same cementite particle, similar to the case of cementite annealed for $5 \mathrm{~h}$ at $500^{\circ} \mathrm{C}$ (Photo. 4). Photograph 6 shows a microstructure of cementite annealed for $1 \mathrm{~h}$ at $700^{\circ} \mathrm{C}$. As seen in the photograph (a), the density of lattice defects differs in the three regions indicated by the marks of A, B and C. Photographs (b), (c) and (d) show three electron diffraction patterns taken from the regions of $A, B$ and $C$, respectively. The incident direction of electron beam is nearly parallel to $[\overline{1} 22]_{\theta}$ and there is no appreciable difference in the crystal orientations among these regions. However, a difference is observed in the reflection spots: in the region $\mathrm{A}$, where a relatively high density of dislocation are still left, the diffraction spots are splitted, while in the region $\mathrm{C}$, where few dislocations exist, the Kikuchi lines appear distinctly. These results show that the annihilation of dislocations occurs inhomogeneously in the cementite particle.

Photograph 7(a) and (b) show examples of extensive dislocation networks formed by annealing at $700^{\circ} \mathrm{C}$ for $1 \mathrm{~h}$ and $15 \mathrm{~h}$ respectively. These networks lie nearly on $(001)_{\theta}$ which is one of the slip planes of cementite $^{(1) \sim(4)(19)}$. The average spacing between the dislocations is estimated to be 1000 - 


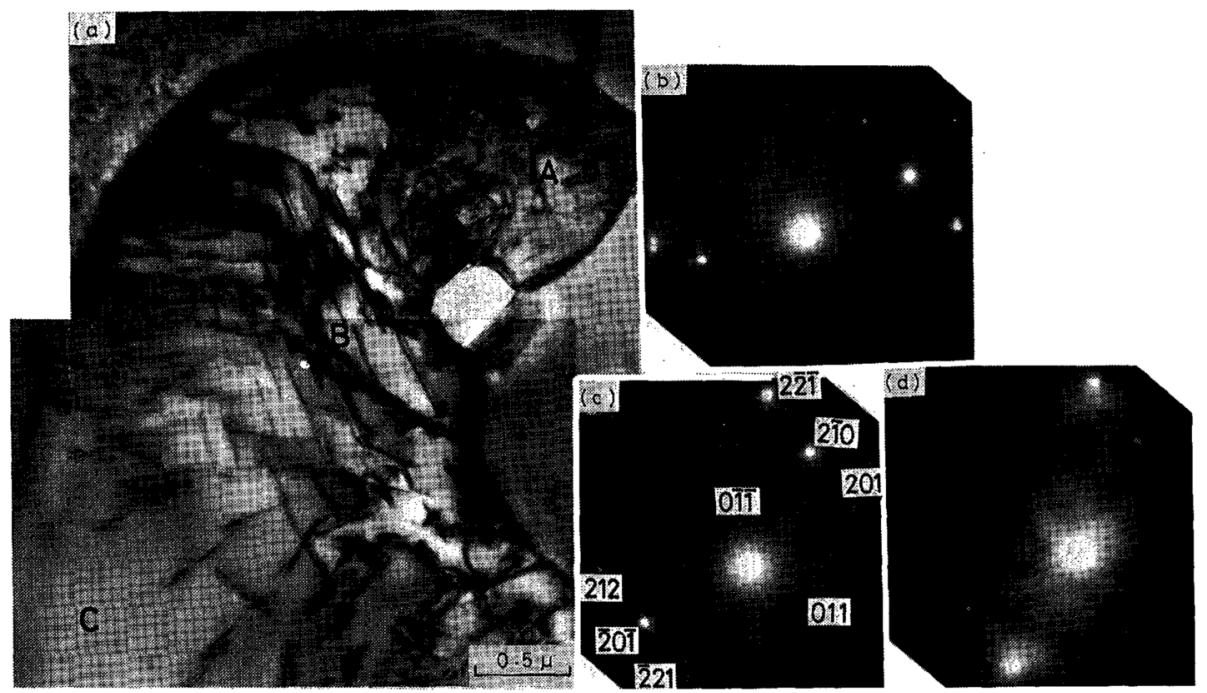

Photo. 6 (a) Transmission electron micrograph showing the recovery of cementite in $1.25 \% \mathrm{C}$ steel annealed for $1 \mathrm{~h}$ at $700^{\circ} \mathrm{C}$ after $92 \%$ cold rolling. (b), (c) and (d). Selected area deffraction patterns taken from the region $\mathrm{A}, \mathrm{B}$ and $\mathrm{C}$, respectively.
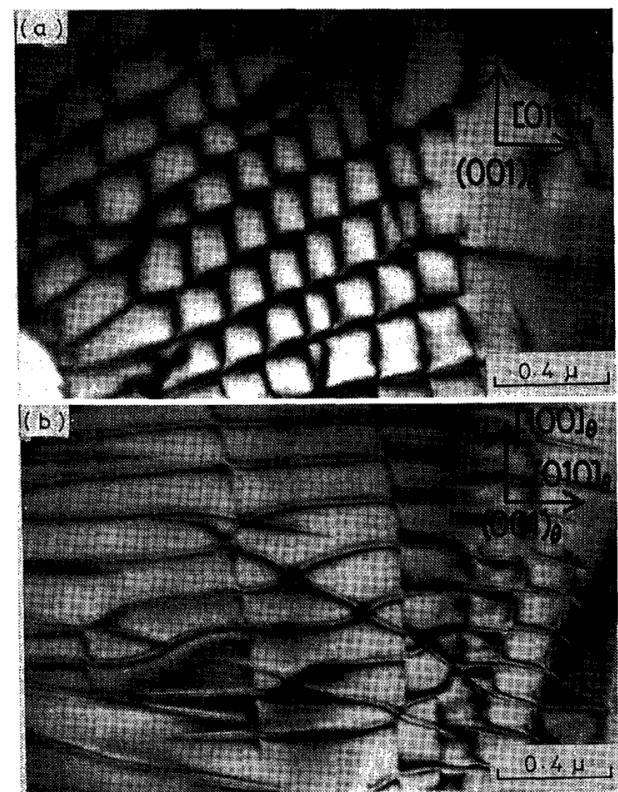

Photo. 7 Transmission electron micrographs showing the formation of subboundaries in cementites in $1.25 \% \mathrm{C}$ steel annealed at $700^{\circ} \mathrm{C}$ for $1 \mathrm{~h} \mathrm{(a)} \mathrm{and}$ $15 \mathrm{~h}$ (b) after $92 \%$ cold rolling.

$4000 \AA$ after annealing for $1 \mathrm{~h}$ and 1600 $8000 \AA$ after annealing for $15 \mathrm{~h}$. In the present observations, all of the extensive dislocation networks are observed only on the $(001)_{\theta}$ plane.
As described above, the annihilation behavior of lattice defects in the cementite particles with diameters of more than several $\mu \mathrm{m}$ is inhomogeneous, and this is different from the case in metals such as $\alpha$-iron ${ }^{(17)(18)}$ and silicon-iron ${ }^{(13)(14)(20) \sim(22)}$. In the case of metals, the recrystallization proceeds mainly from the migration of subboundaries or coalescence of subgrains. In the case of cementite, on the other hand, a number of dislocations introduced by deformation decrease gradually by their climbing or cross slipping as the annealing temperature and time increase. This annihilation temperature depends on the size of cementite particles, that is, it decreases with decreasing particle size. This seems to be associated with a local difference of internal strains introduced in the cementite particles by cold rolling.

From many electron micrographs, the dislocation density in cementite was measured as a function of annealing temperature. Figure 2 shows the result. The annealing time is $5 \mathrm{~h}$ and the average thickness of foils is about $1000 \AA$. The measurements were carried out by the aid of both Ham's method ${ }^{(23)}$ and Ham and Sharpe's method ${ }^{(24)}$. There is no considerable change in the density at annealing temperatures lower than $400^{\circ} \mathrm{C}$. Above $500^{\circ} \mathrm{C}$ 


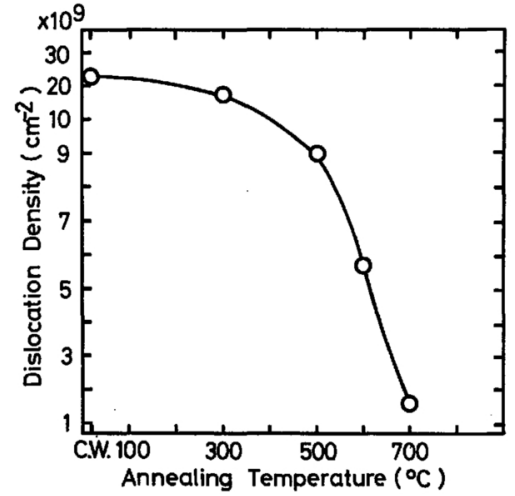

Fig. 2 Change in the average dislocation density of cementite in $1.25 \% \mathrm{C}$ steel by annealing for $5 \mathrm{~h}$ at various temperatures after $92 \%$ cold rolling. C.W.: Cold Working.

the density begins to decrease. It can be said therefore that the recovery of cementite occurs at the temperatures higher by about $200^{\circ} \mathrm{C}$ than that of the ferrite matrix.

\section{X-ray and thermomagnetic analyses}

Although transmission electron microscopy is powerful for studying the structural changes in cementite, the information obtained is obtained from the limited areas. Therefore, we performed X-ray and thermomagnetic analyses to obtain further information on the recovery of cementite in steels. The change in the integrated breadth of each diffraction peak of 113,122, 112 and 021 from cementite is shown in Fig. 3 as a function of annealing temperature. Since the separations of the peaks 113 and 122 and of the 112 and 021 were difficult, the breadths were determined from the integrated breadths of overlapped peaks. All the integrated breadths begin to decrease rapidly near $300^{\circ} \mathrm{C}$. A similar behavior is also observed in the diffraction peak positions as shown in Fig. 4, where the peak positions of 122,112 and 113 are plotted as a function of annealing temperature. All the peak positions shift toward the high reflection angle side by cold rolling. This is probably due to a compressive strain introduced into cementite by cold rolling ${ }^{(25)}$. The release of this strain begins to occur markedly at about $300^{\circ} \mathrm{C}$. This temperature is lower than the temperature

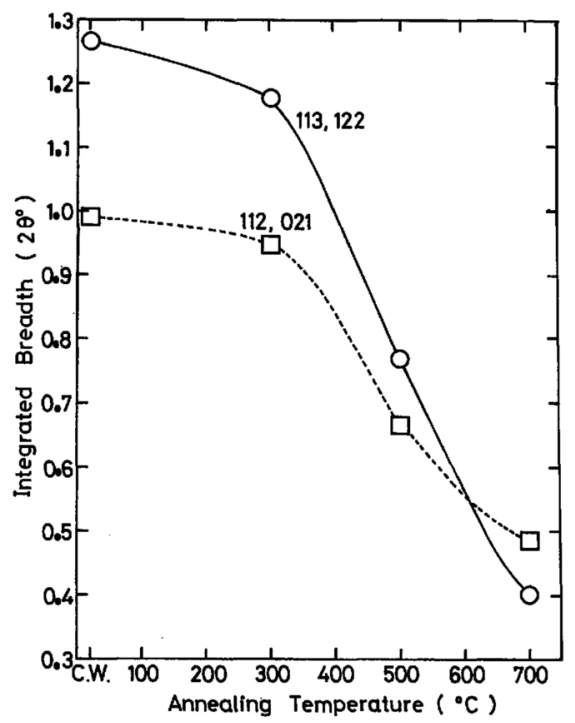

Fig. 3 Change in the integrated breadth of diffraction lines of cementite in $1.25 \% \mathrm{C}$ steel by annealing for $5 \mathrm{~h}$ at various temperatures after $92 \%$ cold rolling. C.W.: Cold Working.

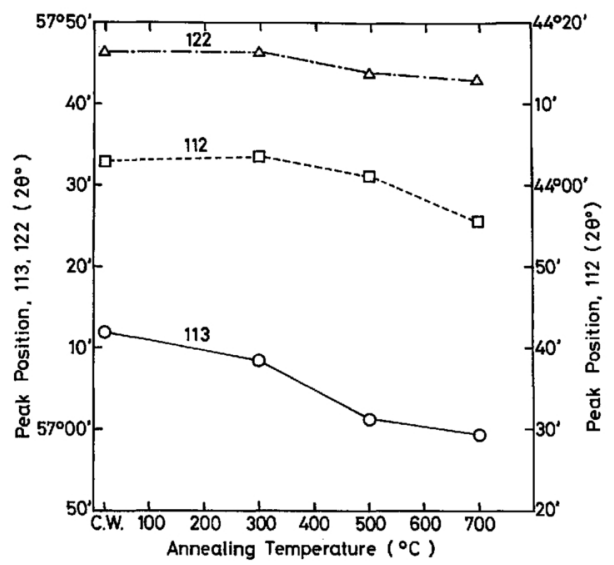

Fig. 4 Change in the peak positions of diffraction lines of cementite by annealing for $5 \mathrm{~h}$ at various temperatures after $92 \%$ cold rolling. C.W.: Cold Working.

at which a remarkable decrease of the dislocation density begins. This may be due to the fact that the X-ray analysis gives mainly the information on the elastic strain. Therefore, it seems that the elastic strain is released prior to the rearrangement or annihilation of dislocations.

The Curie point of cementite in $1.25 \% \mathrm{C}$ steel after $92 \%$ cold rolling was also measured 
as a function of annealing temperature. The result is shown in Fig. 5. The Curie point rises from 210 to about $250^{\circ} \mathrm{C}$ by cold rolling as reported in previous work on carbon steels $^{(26)(27)}$. The most remarkable decrease of Curie point by annealing occurs in the temperature range between 300 and $500^{\circ} \mathrm{C}$, similar to the result by X-ray analysis.

As is evident from Figs. 4 and 5, the strain recovery of cementite is incomplete even after the annealing for $5 \mathrm{~h}$ at $700^{\circ} \mathrm{C}$. This is compatible with the fact that small numbers of

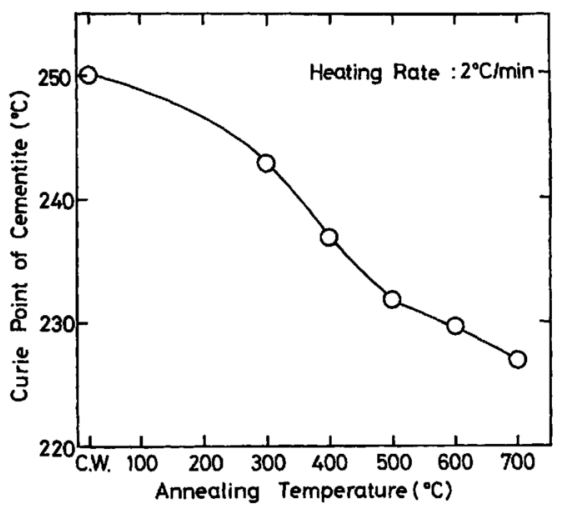

Fig. 5 Curie point of cementite in $1.25 \% \mathrm{C}$ steel annealed for $5 \mathrm{~h}$ at various temperatures after $92 \%$ cold rolling. C.W.: Cold Working. dislocations still remain in the cementite annealed for $15 \mathrm{~h}$ at $700^{\circ} \mathrm{C}$ as seen in Photo. 7 .

Based on the above results obtained from various experimental methods such as optical and transmission electron microscopy, X-ray and thermomagnetic analyses, the recovery processes of lattice defects in cementite and in ferrite in cold-rolled $1.25 \% \mathrm{C}$ steel are summarized in Table 2 . The recovery and recrystallization of ferrite take place in the range between about 300 and $400^{\circ} \mathrm{C}$. Accompanied by the recrystallization of ferrite, the Vickers hardness and the ultimate tensile strength of steel are rapidly decreased as seen in Fig. 1. In cementite, on the other hand, the elastic strain introduced by deformation is released in the range of about 300 to $500^{\circ} \mathrm{C}$, as suggested from data on the Curie point and the X-ray diffraction lines of cementite as well as from the disappearance of strain markings in cementite by transmission electron microscopy. At about $600^{\circ} \mathrm{C}$ at which the coalescence and spheroidization of cementite become remarkable, a marked decrease in the dislocation density and the formation of well-developed subboundaries take place in cementite. This temperature is in fair agreement with the temperature where the deformability of cementite

Table 2 The structural change in ferrite and cementite in $1.25 \% \mathrm{C}$ steel by annealing for $5 \mathrm{~h}$ at various temperatures after $92 \%$ cold rolling.

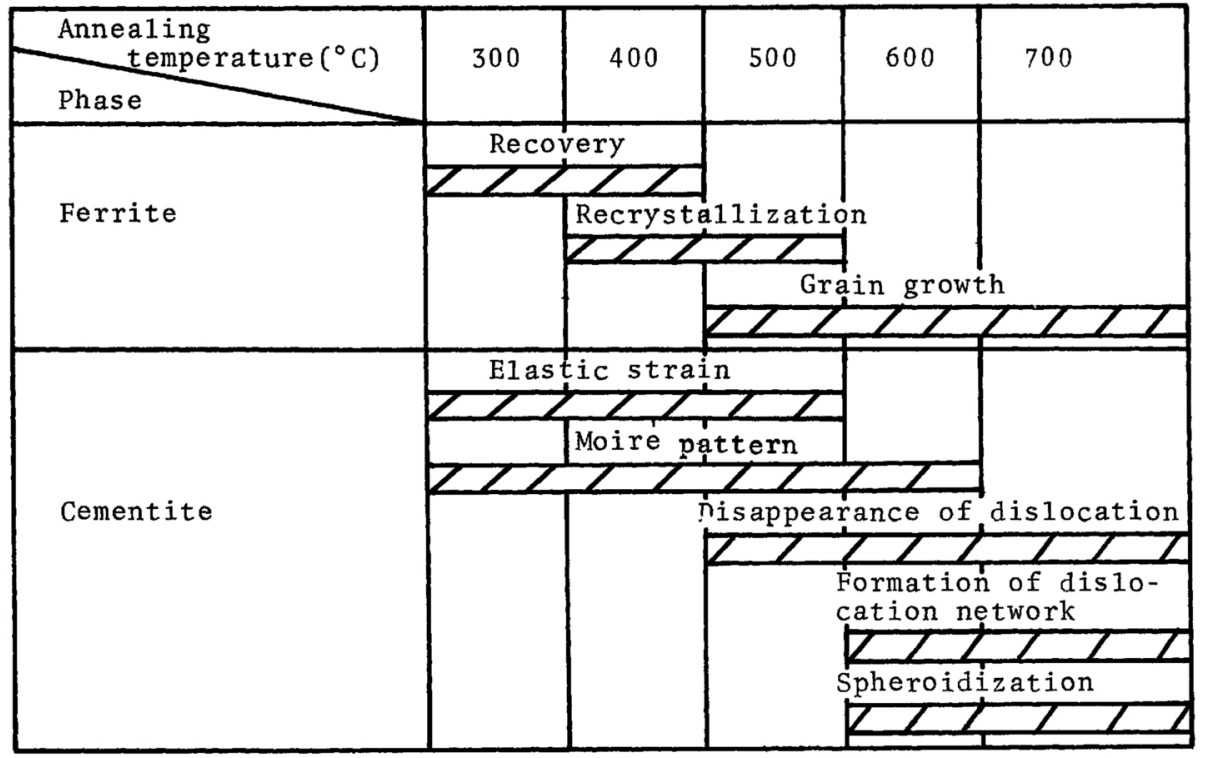


increases remarkably, as reported by the present authors $^{(2)(4)(6)}$. This information seems to be very important in understanding the warmworkability of high carbon steels containing cementite.

\section{Summary}

Transmission electron microscopic observations were made on lattice defects in cementite in $1.25 \% \mathrm{C}$ steel annealed after $92 \%$ cold rolling. Thermomagnetic and X-ray analyses were also performed as additional examinations. The results obtained are summarized as follows:

(1) In the case of isochronal annealing for $5 \mathrm{~h}$ in the temperature range from 200 to $700^{\circ} \mathrm{C}$, no obvious changes in the defect structures of cementite take place at temperatures below $400^{\circ} \mathrm{C}$. Annealing at higher temperatures results in the disappearance of the moiré pattern, a remarkable decrease of dislocation density and the formation of well-developed subboundaries. These defects disappear as the spheroidization takes place at temperatures above $600^{\circ} \mathrm{C}$. The results suggest that the recovery of lattice defects is caused by polygonization accompanied by climbing or cross slipping of dislocations.

The recovery of lattice defects in the ferrite matrix proceeds by annealing below about $400^{\circ} \mathrm{C}$, and its recrystallization starts from about $400^{\circ} \mathrm{C}$ and is completed at about $500^{\circ} \mathrm{C}$. The growth of ferrite grains takes place at temperatures higher than $500^{\circ} \mathrm{C}$.

(2) Isothermal annealing was carried out for various periods up to $15 \mathrm{~h}$ at $700^{\circ} \mathrm{C}$. A remarkable decrease of dislocation density and the formation of subboundaries in cementite take place after annealing for 0.5 or $1 \mathrm{~h}$. With increasing the annealing time from 5 to $15 \mathrm{~h}$, the spacing between the dislocations constituting subboundaries increases slightly. On the other hand, the recrystallization of the ferrite matrix is completed within the annealing time of $0.5 \mathrm{~h}$.

(3) X-ray and thermomagnetic analyses indicate that a considerable decrease in the integrated breadth, slight shifts in the diffraction peak positions and a decrease in Curie point occur at the annealing temperatures of 300 to $500^{\circ} \mathrm{C}$. These facts suggest that the elastic strain in cementite is released in this temperature range.

\section{REFERENCES}

(1) A. Inoue, T. Ogura and T. Masumoto: J. Japan Inst. Metals, 37 (1973), 875; Trans. JIM, 17 (1976), 149.

(2) A. Inoue, T. Ogura and T. Masumoto: Bull. Japan Inst. Metals, 13 (1974), 653.

(3) A. Inoue, T. Ogura and T. Masumoto: Scripta Met., 11 (1977), 1.

(4) A. Inoue, T. Ogura and T. Masumoto: Trans. JIM, 17 (1976), 663.

(5) A. Inoue and T. Masumoto: Trans. ISIJ, 17 (1977), 143.

(6) A. Inoue, T. Ogura and T. Masumoto: Met. Trans., (1977), in press.

(7) T. Sato and T. Nishizawa: J. Japan Inst. Metals, 19 (1955), 385.

(8) F. B. Pickering: Iron and Steel, 36 (1965), 110.

(9) T. Ueda and K. Asakura: J. Japan Soc. Testing Mater., 6 (1957), 386.

(10) T. Ueda and M. Tanaka: ibid., 9 (1960), 569.

(11) J. E. Bailey: Phil. Mag., 5 (1960), 833.

(12) J. E. Bailey and P. B. Hirsch: ibid., 5 (1960), 485.

(13) H. Hu and A. Szirmae: Trans. Met. Soc. AIME, 221 (1961), 839.

(14) H. Hu: ibid., 224 (1962), 75.

(15) H. Fujita: J. Phys. Soc. Japan, 16 (1961), 397.

(16) P. B. Hirsch, A. Howie, R. B. Nicholson and D. W. Pashley: Electron Microscopy of Thin Crystals, London Butterworths, (1969), p. 119.

(17) Y. Taneda: J. Appl. Phys. Japan, 4 (1965), 16.

(18) K. Yuasa and S. Koda: J. Japan Inst. Metals, 31 (1967), 646.

(19) A. S. Keh: Acta Met., 11 (1963), 1101.

(20) J. L. Walter and E. F. Koch: Acta Met., 10 (1962), 1059.

(21) J. L. Walter and E. F. Koch: ibid., 11 (1963), 923.

(22) E. Furubayashi: Trans. ISIJ, 9 (1969), 222.

(23) R. K. Ham: Phil. Mag., 6 (1961), 1183.

(24) R. K. Ham and N. G. Sharpe: ibid., 6 (1961), 1193.

(25) B. D. Cullity: Elements of X-ray Diffraction, Addison-Wesley Publishing Company, (1959), p. 264.

(26) D. V. Wilson: Nature, 167 (1951), 809.

(27) D. V. Wilson: Trans. ASM, 47 (1955), 321. 